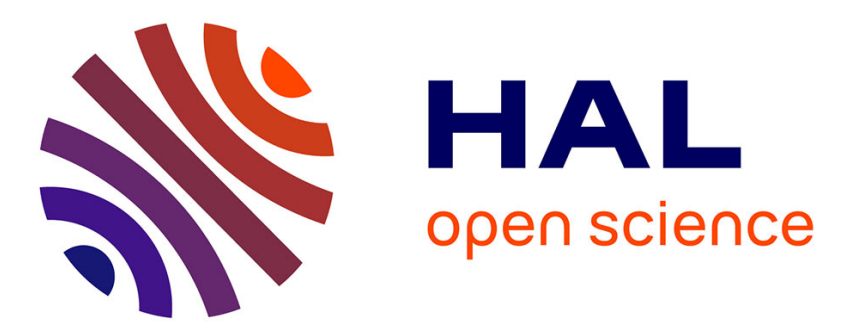

\title{
Cyclic and monotonic testing of free and constrained recovery properties of a chemically crosslinked acrylate
} Juan-Sebastian Arrieta, Julie Diani, Pierre Gilormini

\section{To cite this version:}

Juan-Sebastian Arrieta, Julie Diani, Pierre Gilormini. Cyclic and monotonic testing of free and constrained recovery properties of a chemically crosslinked acrylate. Journal of Applied Polymer Science, 2014, 131, pp.39813-39820. 10.1002/app.39813 . hal-00948096

\section{HAL Id: hal-00948096 https://hal.science/hal-00948096}

Submitted on 26 Feb 2014

HAL is a multi-disciplinary open access archive for the deposit and dissemination of scientific research documents, whether they are published or not. The documents may come from teaching and research institutions in France or abroad, or from public or private research centers.
L'archive ouverte pluridisciplinaire HAL, est destinée au dépôt et à la diffusion de documents scientifiques de niveau recherche, publiés ou non, émanant des établissements d'enseignement et de recherche français ou étrangers, des laboratoires publics ou privés. 


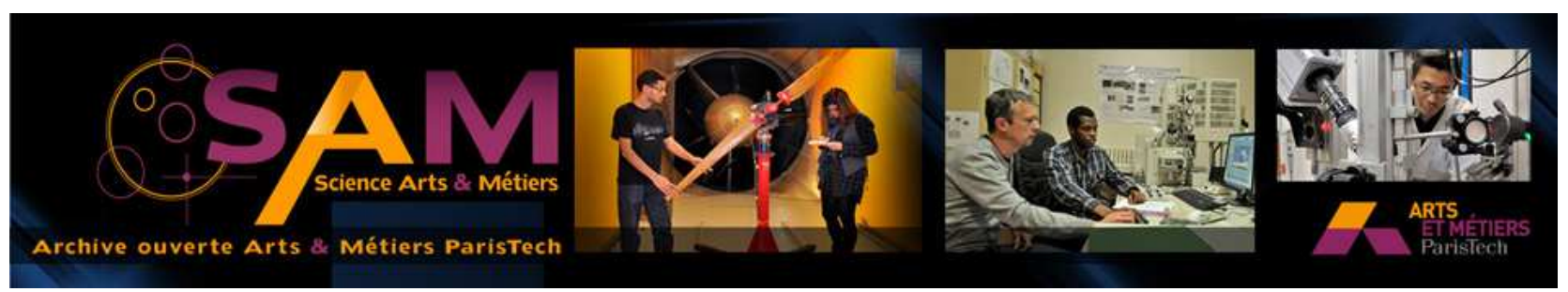

Science Arts \& Métiers (SAM)

is an open access repository that collects the work of Arts et Métiers ParisTech researchers and makes it freely available over the web where possible.

This is an author-deposited version published in: http://sam.ensam.eu

Handle ID: .http://hdl.handle.net/10985/7759

\section{To cite this version :}

Juan Sebastian ARRIETA, Julie DIANI, Pierre GILORMINI - Cyclic and monotonic testing of free and constrained recovery properties of a chemically crosslinked acrylate - Journal of Applied Polymer Science - Vol. 131, p.39813-39820 - 2014 


\title{
Cyclic and monotonic testing of free and constrained recovery properties of a chemically crosslinked acrylate
}

J. Sebastian Arrieta*, Julie Diani, Pierre Gilormini

Msc. J. Sebastian Arrieta, Dr. Julie Diani, Dr. Pierre Gilormini

Laboratoire PIMM, CNRS, Arts et Métiers ParisTech, 151 bd. de l'Hôpital, 75013 Paris, France

Correspondence to: Sebastian Arrieta, E-mail: juan-sebastian.arrieta-escobar@ensam.eu

\begin{abstract}
A chemically crosslinked acrylate network was submitted to various thermomechanical strain and stress recoveries while changing the experimental parameters in order to better define the benefits and the limits of using chemically crosslinked polymers for multicycle applications or applications under external constraints. The results showed that the free recoveries and the constrained recoveries remained the same at the first cycle and during the next ones. It was also shown that the low stress usually generated by a crosslinked network when submitted to a constrained recovery can be significantly increased by choosing suitable experimental conditions.
\end{abstract}

\section{KEYWORDS}

Amorphous network; Shape memory polymer; Recovery; Cyclic tests; Thermal properties

\section{INTRODUCTION}

Shape memory polymers (SMPs) have drawn substantial attention recently due to their actual and potential applications. ${ }^{1-7}$ Research interests focus on both experimental characterization ${ }^{8-}$ 
12 among others, and modeling development (see reviews ${ }^{13,14}$ ). The current contribution addresses, from an experimental perspective, two major problems that may be encountered when designing shape memory applications for chemically crosslinked polymers. First, are the shape memory properties exhibited by these materials at the first thermomechanical cycle reproducible during subsequent cycles? This question is of interest when these smart materials are used for multicycle applications. Second, chemically crosslinked polymers are known to generate a small stress when recovering their temporary shape, which is a main drawback when they are submitted to an external constraint like in the case of a stent within an artery. Actually, the external constraint might prevent the material shape recovery. Therefore, the issue is to define the best experimental conditions in favor of increasing the stress generated by the material during shape recoveries.

In terms of multicycle thermomechanical shape recovery tests, physically crosslinked polyurethane reported shape recoveries that could reduce with the number of cycles. ${ }^{15} \mathrm{~A}$ composite silicone-poly( $\varepsilon$-caprolactone) polymer submitted to three uniaxial tension strain memory cycles, showed strain recoveries with respect to temperatures that superpose for the material deformed at high temperatures. ${ }^{16}$ Chemically crosslinked polyurethanes submitted to four thermomechanical cycles reported qualitatively good shape fixity and complete shape recovery. ${ }^{17}$ The effect of strain recovery cycles for epoxy networks deformed to their temporary shape at temperatures above and below the rubbery states was tested. Differences in the material cyclic behavior at moderately low temperatures, driving to lower pre-strain at the second cycle when the temporary shape was set at constant stress were noted. ${ }^{18,19}$ Finally, cyclic shape memory thermocycles with free or constrained recovery steps on a crosslinked polyurethane submitted to its temporary shape at high temperatures above the glass transition were presented by Volk et al. ${ }^{20}$ The comparison of the free recoveries and the constrained recoveries between cycles 1 and 2 appears in the form of a table comparing only two specific stress-strain states along the thermomechanical cycles. In order to complement the literature 
experimental data, free recoveries and constrained recoveries are compared in this paper for up to four cycles when the temporary deformation had been applied at high or moderately low temperatures. Results are discussed in regards to the material stress-strain behavior evolution along the cycles.

The resulting stress with respect to temperature while the pre-strain is maintained constant was first displayed for shape memory polymers maintained in a bending state of strain. ${ }^{21}$ The tests were run on crosslinked acrylate network and the pre-strain was applied below and above the glass transition temperature. When the strain was applied at a temperature below the rubbery state, the specimen exhibited a significant stress peak at the glass transition temperature. For samples deformed in the rubbery state, the stress curve with respect to temperature showed a sigmoidal form and the final stress matched with the material behavior at the final temperature. An epoxy network, uniaxially constrained in tension and in compression at a temperature well above the rubbery state was studied. ${ }^{9}$ During constrained recovery tests, measures of stress with respect to temperature exhibited a compression state at moderately low temperature due to the impeded thermal expansion, then a sigmoidal form ending with the stress resulting from the material behavior at the applied strain and temperature. Later, the effects of the cooling rate and of the heating rate on the stress vs. temperature response of samples submitted to compressions at moderately low temperatures was reported, ${ }^{11}$ and a little effect of the cooling rate and an increase of the stress peak when increasing the heating rate. However, it may be noted that at the end of the cooling and at the beginning of the heating these experimental results do not show the expected stress and the experimental data are truncated. This is due to the mixed conditions including constrained recovery at high temperatures and free recovery at low temperatures. Finally, it was observed on a crystalline polymer that increasing the applied strain increases the stress peak. ${ }^{22}$ Extensive experimental results reveal that the stress peak increases when lowering the temperature at which the strain is applied and with reducing stress relaxation duration at the 
loading temperature. It was also observed that these variations did not depend on the storage time at low temperature. ${ }^{23}$ The latter experimental data were obtained on specimen strained at $100 \%$ and very little or no compression was measured at the beginning of the heating, which is inconsistent and remains to be understood. ${ }^{9}$ However, an extended storage time at low temperature (up to 14 days), should affect the material shape recovery. ${ }^{24}$ Therefore, the largest possible pre-strain should be applied at the lowest temperature and the shape memory polymer should be heated fast in order to generate the maximum stress peak. These three experimental parameters have been tested on our acrylate network and although the above statement is theoretically right, it should be balanced by the poor fixity that may be obtained at low temperatures and by the sample break during heating when highly deformed at low temperatures. The effect of structural relaxation has been tested also.

In the following, we present a series of original experimental results obtained on an acrylate network that was synthesized in lab. The material was submitted to uniaxial thermomechanical cycles. The pre-strain was applied at various temperatures, in the rubbery state and below, and stored at room temperature (well below the glass transition). Then, the pre-strained samples were submitted to free recoveries or constrained recoveries at various heating rates from room temperature to high temperature. The material, experiments and results are presented and discussed in the next sections.

\section{EXPERIMENTAL}

\section{Material}

An acrylate polymer network was synthetized in the laboratory using a composition previously proposed. ${ }^{25}$ The material is obtained by photopolymerization of benzyl methacrylate (BMA) added with $550 \mathrm{~g} / \mathrm{mol}$ molar weight poly(ethylene glycol) dimethacrylate (PEGDMA) that serves as crosslinker. A mix of $90 \%$ in mol of BMA, $10 \%$ in mol of PEGDMA and 0.5\% of 2-dimethoxy-2-phenylacetophenone (DMPA) as photoinitiator 
is set to polymerize for 50 minutes in an ultra violet chamber UVP CL-1000. Final products are rectangular plates of $1.3 \mathrm{~mm}$ thickness. The material viscoelasticy temperature range was characterized in tension by performing a temperature sweep of $2{ }^{\circ} \mathrm{C} / \mathrm{min}$ while submitting the material to dynamic mechanical analysis (DMA) at $1 \mathrm{~Hz}$. The test was performed on a TMA Q800 from TA instruments. Figure 1 show the storage Young modulus and the damping factor, resulting from the DMA temperature sweep. It may be noted that the material viscoelasticity extends from 40 to $80^{\circ} \mathrm{C}$. The glass transition temperature measured by differential scanning calorimetry (DSC) at a heating ramp of $10{ }^{\circ} \mathrm{C} / \mathrm{min}$ was located at $46^{\circ} \mathrm{C}$.

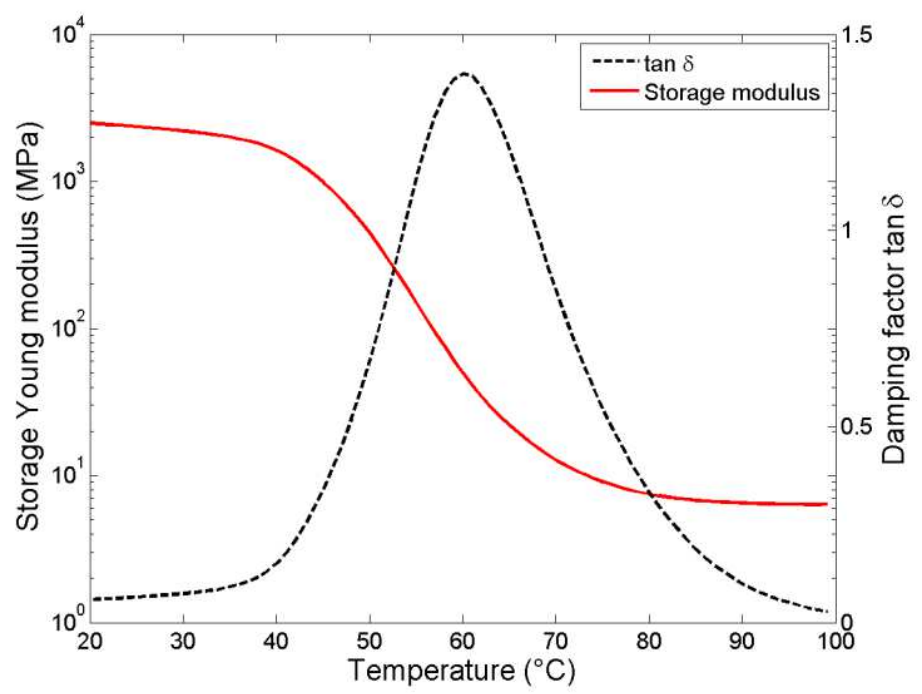

Figure 1: Dynamic mechanical analysis temperature sweep from $20^{\circ} \mathrm{C}$ to $100^{\circ} \mathrm{C}$ at $2{ }^{\circ} \mathrm{C} / \mathrm{min}$ and $1 \mathrm{~Hz}$.

\section{Thermomechanical cycle experimental set up}

Dogbone samples $4 \mathrm{~mm}$ wide and $25 \mathrm{~mm}$ long were cut in the acrylate plates. Specimens were submitted to classic thermomechanical recovery cycles performed on an Instron 5881 tension machine equipped with an environmental chamber capable of applying accurate heat ramps. Local strains were measured by video extensometry, and stresses were measured with a $1 \mathrm{kN}$ load cell. Except when mentioned otherwise, strains were applied at a constant crosshead speed of $10 \mathrm{~mm} / \mathrm{min}$. A typical thermocycle consists of 4 steps:

Step 1: Sample heating at the desired temperature and pre-straining, 
Step 2: Sample cooling to a temperature below the onset of the glass transition temperature while its strain is maintained constant,

Step 3: Stresses releasing; the strain applied during step 1 keeps stored due to the material lower molecular mobility in the glassy state,

Step 4: The sample undergoes a free recovery when heated, or the stored strain is maintained and constrained recovery is recorded as the sample is heated. The heating procedure consists in applying a constant temperature ramp.

The thermomechanical cycle depends on various experimental parameters. In the following, the main focus will be on the temperature at which the strain is applied, which classically should be chosen above the temperature of the onset of the glass transition $\left(40{ }^{\circ} \mathrm{C}\right.$ for our material), on the amount of applied strain, and on the temperature heating rate during step 4. Material stress relaxation during or after the applied pre-strain will also be monitored as in the case of constrained recovery.

First, we consider cyclic free recoveries and constrained recoveries for samples submitted to temporary stretching at high temperature $\left(65^{\circ} \mathrm{C}\right)$ and moderately low temperature $\left(45^{\circ} \mathrm{C}\right)$. We define a moderately low temperature as the temperature where the material deformation mechanisms are no longer due to entropy changes only. For this purpose, each sample is submitted to four consecutive thermomechanical cycles during which the material stressstrain responses are recorded during step 1, and the free recoveries or constrained recoveries during step 4 are also monitored. Such experimental results will provide complete data in order to discuss the re-usability of chemically crosslinked polymer networks for shape memory applications.

Second, some specimens are submitted to thermomechanical constrained recoveries varying the temperature of pre-strain application from $35{ }^{\circ} \mathrm{C}$ to $65^{\circ} \mathrm{C}$, the applied strain from $20 \%$ to $55 \%$ during step 1 , and the heating rates from $1{ }^{\circ} \mathrm{C} / \mathrm{min}$ to $10^{\circ} \mathrm{C} / \mathrm{min}$ during step 4 . During the heating ramp, a compression stress may appear due to the hindered thermal expansion, and 
therefore the sample dimensions were chosen in order to prevent buckling. For samples submitted to $20 \%$ strain at $40{ }^{\circ} \mathrm{C}$, the stretching time was also varied in order to study the impact of material relaxation on the stress peak recorded during heating. Another way to study this effect was to let the stress relax at $40{ }^{\circ} \mathrm{C}$ during one hour just after deforming the sample. The results will assess the best experimental conditions to produce the maximum stress during recovery while preserving the sample integrity. Only one experimental result is shown for each test for reading clarity, but every test, cyclic or not, was repeated at least twice in order to discard experimental errors.

\section{RESULTS AND DISCUSSION}

\section{Strain and stress recoveries under cyclic loading conditions}

\section{Pre-strain applied at high temperature in the rubbery state}

This section studies the strain and stress recoveries of the acrylate network submitted to 4 consecutive identical thermomechanical cycles characterized by an applied strain of $20 \%$ at $65{ }^{\circ} \mathrm{C}$ (in the rubbery state) during step 1 , and a heating ramp of $5^{\circ} \mathrm{C} / \mathrm{min}$ during step 4 . Figure 2 shows the material stress-strain responses recorded during each step 1 of the four consecutive cycles. One notices that the material behavior remains identical and unaffected by the consecutive cycles.

Figure 3 shows the material free recoveries during the heating steps. The material strain fixity, characterizing the strain after step 3 over the applied strain, remains $99 \%$ from cycle 1 to cycle 4. Moreover, the material strain recovery is shown to be similar for all cycles, displaying a full strain recovery after $65^{\circ} \mathrm{C}$. These results corroborate the results reported on an epoxy network for tests extending to 20 cycles. ${ }^{18}$

Constrained recovery cycles were also applied during step 4 for the same test conditions and are reported in Figure 4. Only three cycles were obtained, since the samples broke 
systematically during the fourth cycle. It may be noticed that there is no significant difference between the cycles, and that the material exhibits a compression state at the beginning of the heating step, which results from the constrained thermal expansion while heating. At higher temperatures the material undergoes a change of state from glassy to rubbery characterized by a stress evolution toward positive values. At high temperatures, the final stress is in good agreement with the material stress-strain response at the same temperatures. Figure 4 is in accordance with previous results that showed cyclic independency for the constrained recovery of a polyurethane network pre-strained in the rubbery state. ${ }^{20}$ Moreover, such results were expected in regards of the material behavior repeatedly recorded at $65{ }^{\circ} \mathrm{C}$ over the cycles (Figure 2). Figures 2 to 4 show that when submitted to shape memory cycles with a temporary shape applied in the rubbery state, the acrylate exhibits no sign of memory of the previous cycles. Therefore, as long as the material is submitted to cyclic free recovery, identical recoveries at the first cycle and at the subsequent ones are expected. For constrained recoveries, the response does not evolve from one cycle to the next one, but the number of possible cycles is limited.

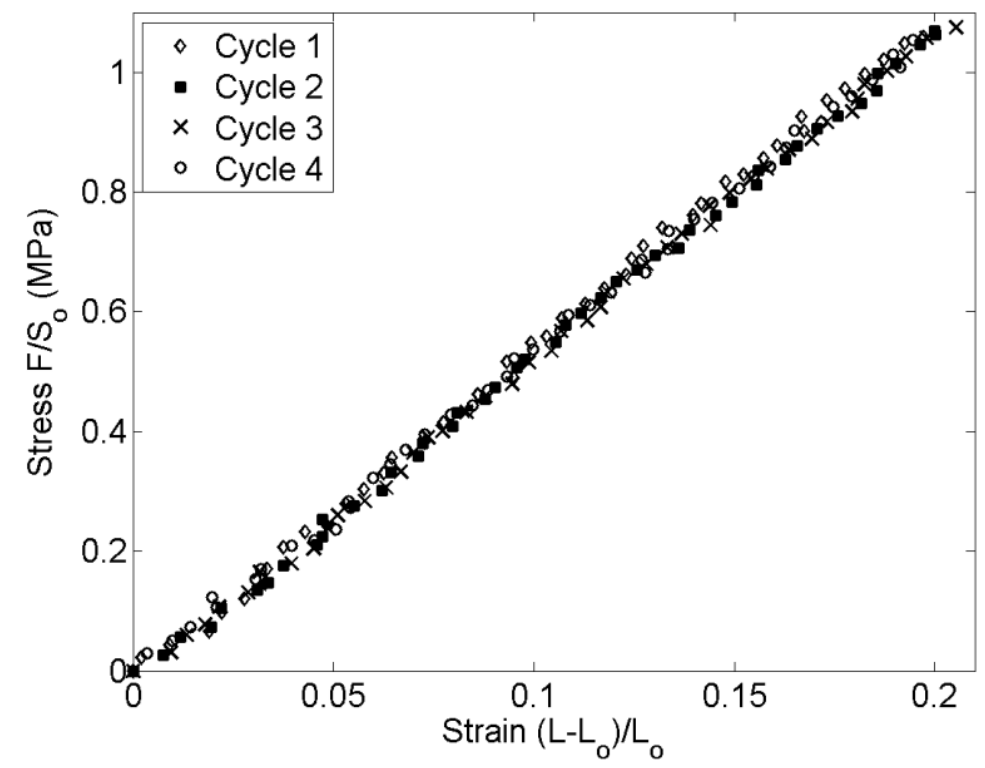

Figure 2: Material stress-strain response in uniaxial tension when deformed up to $20 \%$ at $65^{\circ} \mathrm{C}$ during step 1 of four consecutive thermomechanical cycles. 


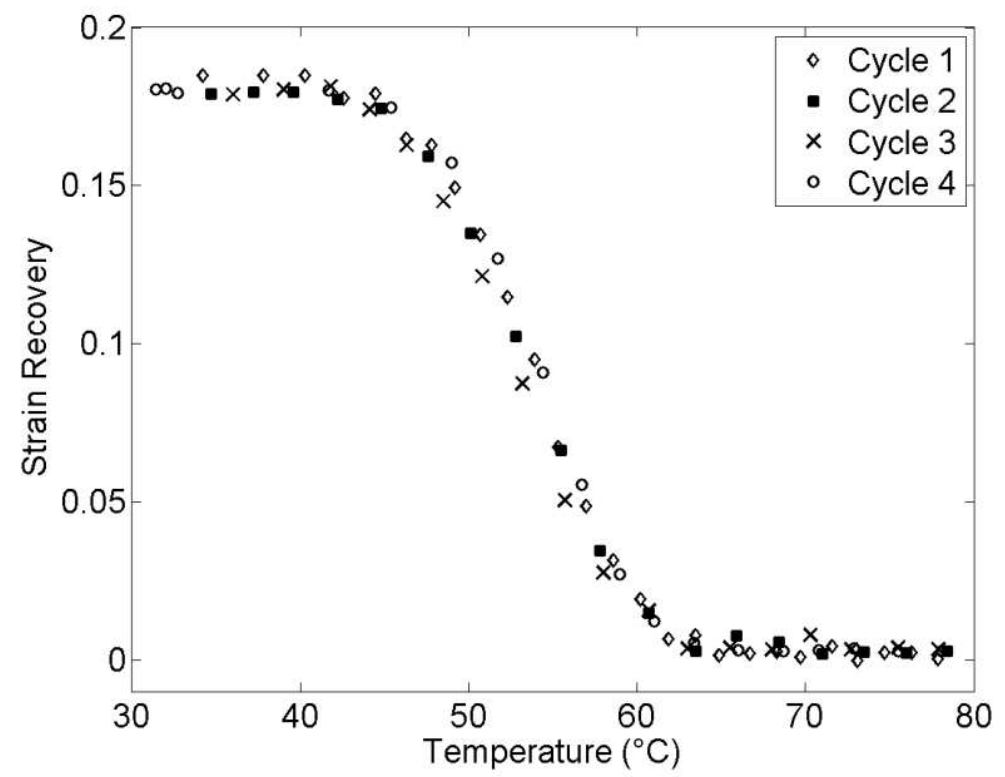

Figure 3: Step 4 free recovery during four consecutive thermomechanical cycles for a sample pre-strained $20 \%$ at $65^{\circ} \mathrm{C}$ and heated at $5^{\circ} \mathrm{C} / \mathrm{min}$.

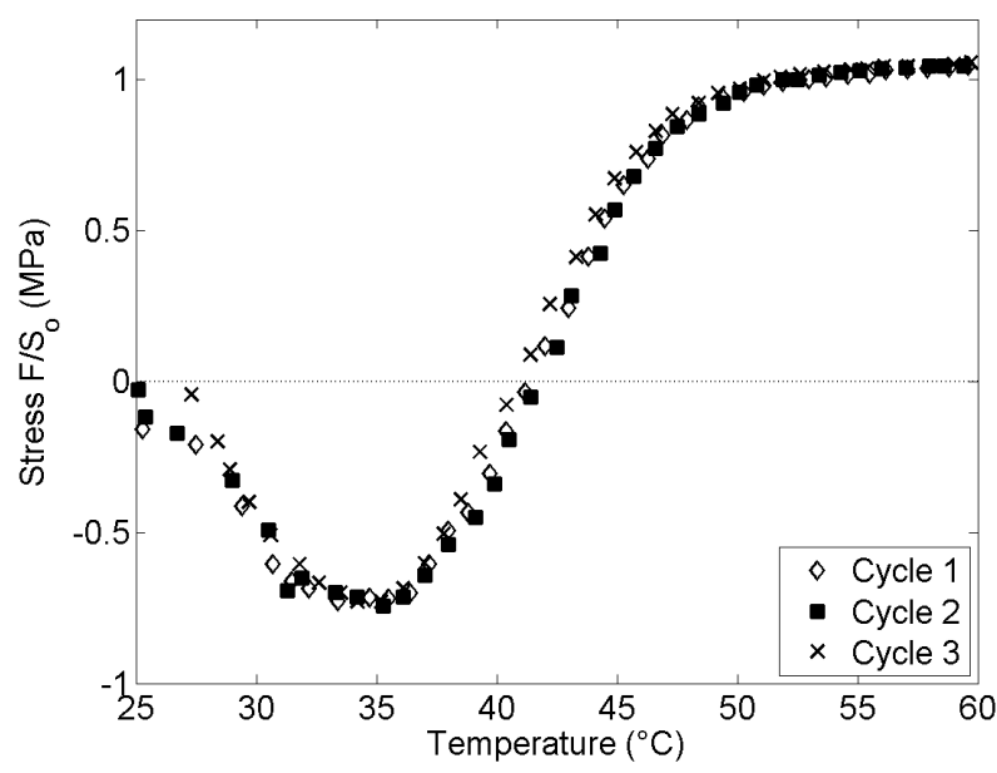

Figure 4: Step 4 constrained recovery during consecutive thermomechanical cycles for a sample pre-strained $20 \%$ at $65^{\circ} \mathrm{C}$ and heated at $5{ }^{\circ} \mathrm{C} / \mathrm{min}$.

Pre-strain applied at moderately low temperature within the viscoelastic transition

The acrylate network is submitted to four consecutive thermomechanical cycles characterized by $20 \%$ strain applied at $45^{\circ} \mathrm{C}$ during step 1 and a constant heating rate of $5{ }^{\circ} \mathrm{C} / \mathrm{min}$ during 
step 4. This test differs from the test run in the previous section by the temperature at which the strain is applied. Temperature $45^{\circ} \mathrm{C}$ stands within the glass transition range (Figure 1). At such a temperature, the macromolecular chains are significantly less mobile than at the higher temperature of $65{ }^{\circ} \mathrm{C}$, which leads to a significantly different material behavior. The material stress-strain responses in uniaxial tension measured at $45{ }^{\circ} \mathrm{C}$ during the steps 1 of the four thermomechanical cycles are presented in Figure 5. The large stress reached at $45{ }^{\circ} \mathrm{C}$ may be noted, compared to the maximum stress of $1 \mathrm{MPa}$ measured at $65{ }^{\circ} \mathrm{C}$. The shape of the material stress-strain response reminds of the behavior of an elasto-plastic behavior. However, the material slowly recovers the whole applied strain when the stress is released. Two hours were required to recover $20 \%$ strain at $45{ }^{\circ} \mathrm{C}$. Therefore, the material behavior is more viscoelastic than elastic-plastic. At the second cycle, the initial stiffness and the elastic limit are enhanced by the previous loading. After the second cycle, the material behavior stabilized and the stress-strain responses corresponding to cycles 3 and 4 superimpose with cycle 2 . Such a cyclic behavior is consistent with the lower strains recorded by Feldkamp and Rousseau $^{10}$ after the first cycle when the same stress was applied during consecutive strain memory cycles.

Figure 6 shows four consecutive free recoveries (step 4) when heating the sample at $5{ }^{\circ} \mathrm{C} / \mathrm{min}$. The material shows a fixity of approximately $97 \%$ along the cycles. Full strain recovery is observed at $45^{\circ} \mathrm{C}$ for the four cycles. More interestingly, the kinetics of recovery is independent of the cycle number. The material strain recovery is complete. The latter result indicates that the material behavior alteration is likely to happen during the first loading only, and the material state does not evolve after the maximum loading is first reached. Similar results were obtained on an epoxy network. ${ }^{10}$

The plot of the constrained recovery of a polymer network pre-strained more than once at moderately low temperature has never been shown in the literature. Considering the change in the material behavior recorded along the cycles (Figure 5), one could intuitively expect a 
constrained recovery change from cycle 1 to cycle 2 . Figure 7 displays the stress recovery (step 4) at constant 20\%-strain. Unlike when the pre-strain is applied at high temperatures, the stress recovery presents a stress peak at the DSC glass transition temperature, approximately $46{ }^{\circ} \mathrm{C}$. At the beginning of the heating ramp, a compression stress is induced by the impeded thermal expansion. Such a compression has never been shown in the literature for samples strained at moderately low temperatures, because of experimental set up limits ${ }^{2,11}$ or large applied strain. $^{23}$

Actually, when increasing the applied strain, the stress takes and keeps positive values at the beginning of heating. Next section will address these results in more details. It is to be noticed that the maximum compression is significantly larger in Figure 7 than in Figure 4. Despite the stress-strain response change from cycle 1 to cycle 2 displayed in Figure 5, the constrained recovery is similar from one cycle to the next one. This reveals that either the stress-strain alteration due to the first load does not affect the material stress recovery with respect to temperature, or this alteration is not significant enough to appear in the stress recovery curve with the precision of the experimental set up.

Finally, constrained recovery seemed a highly damaging test for both loading temperatures $45^{\circ} \mathrm{C}$ and $65^{\circ} \mathrm{C}$, since the samples broke at the fourth cycle consistently, whereas samples submitted to free recovery never broke. 


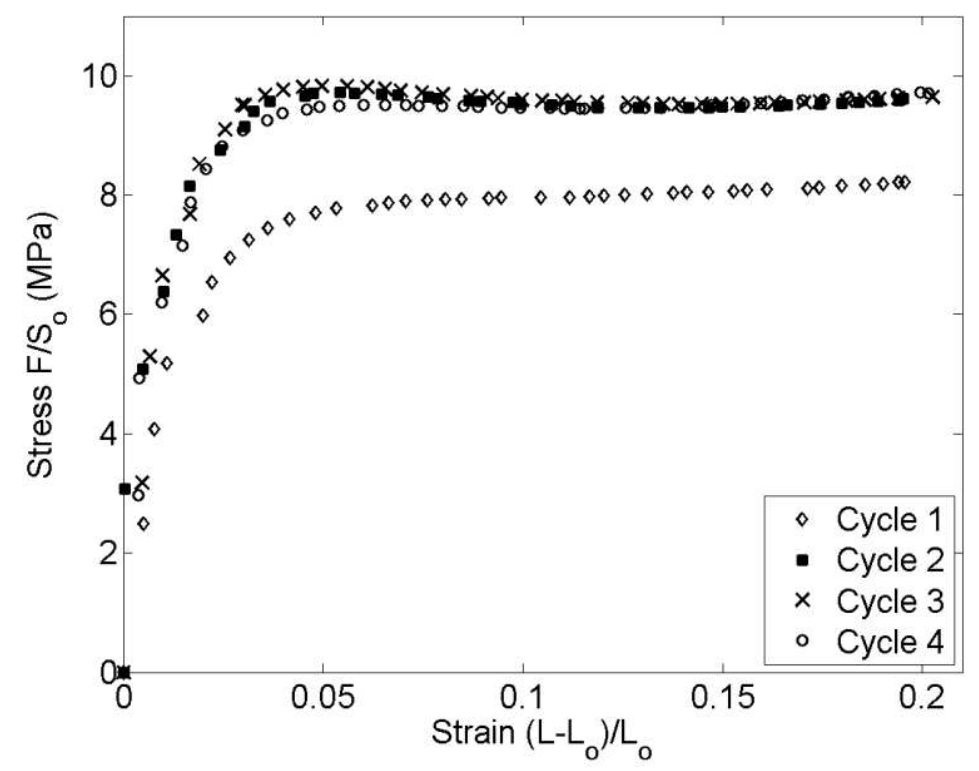

Figure 5: Material stress-strain response in uniaxial tension when deformed up to $20 \%$ at $45^{\circ} \mathrm{C}$ during step 1 of four consecutive thermomechanical cycles.

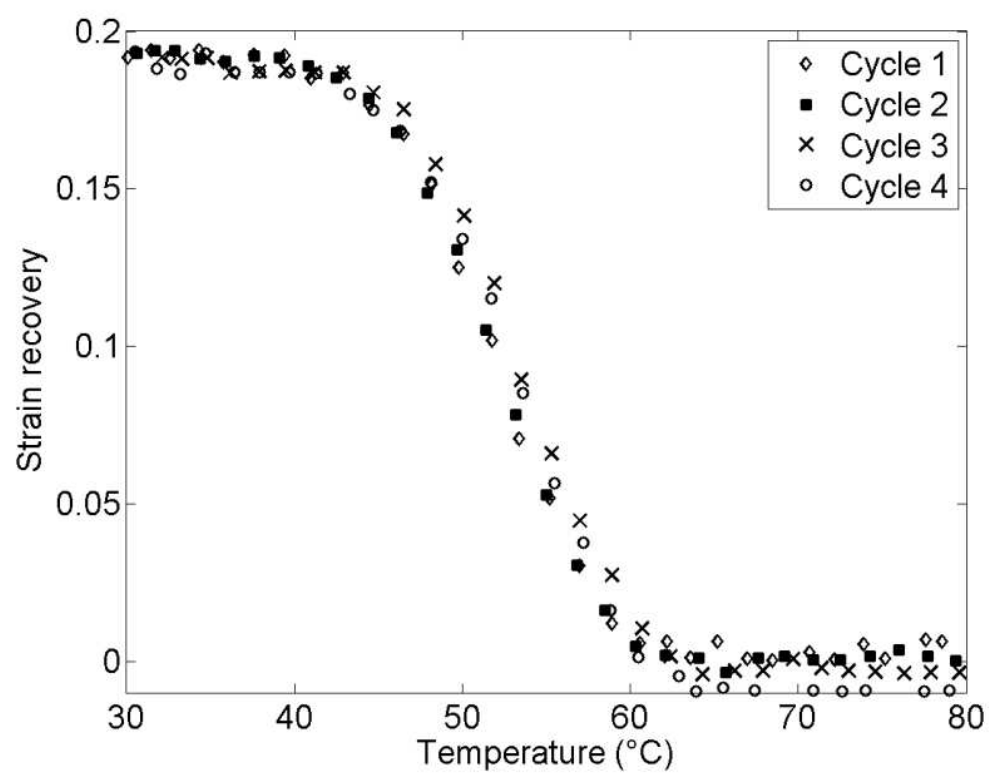

Figure 6: Step 4 free recovery during four consecutive thermomechanical cycles for a sample pre-strained $20 \%$ at $45^{\circ} \mathrm{C}$ and heated at $5{ }^{\circ} \mathrm{C} / \mathrm{min}$. 


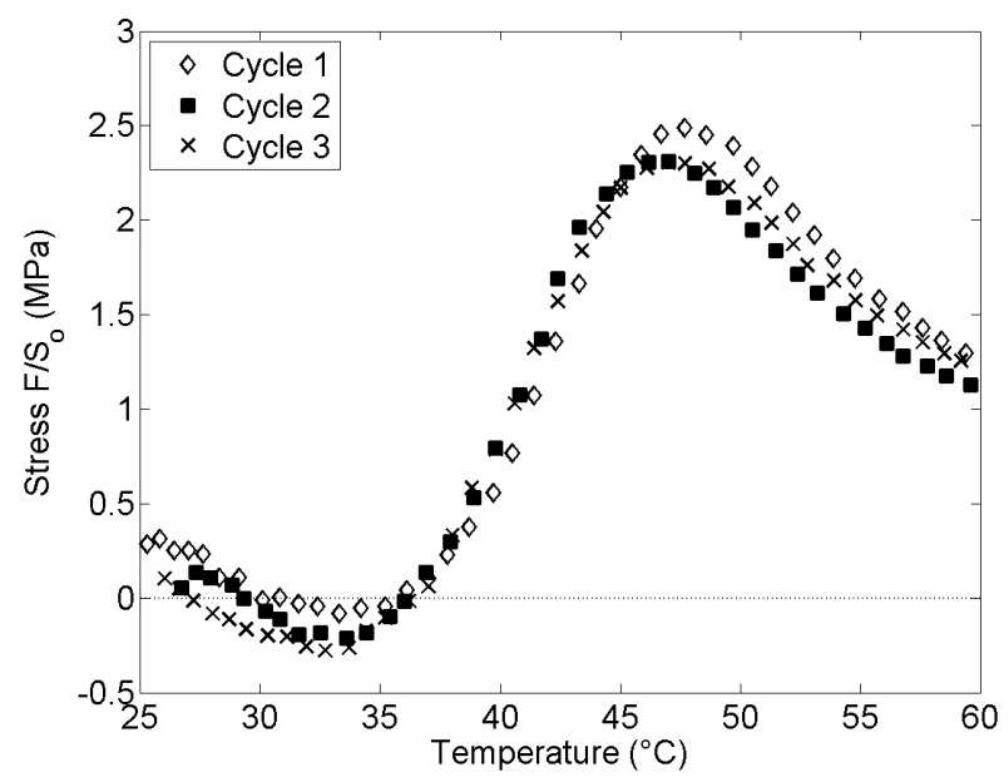

Figure 7: Step 4 constrained recovery during consecutive thermomechanical cycles for a sample pre-strained $20 \%$ at $45^{\circ} \mathrm{C}$ and heated at $5{ }^{\circ} \mathrm{C} / \mathrm{min}$.

An interpretation of the systematic sample failure in cyclic constrained recovery, may be based on the failure envelope of Smith. ${ }^{26}$ The latter characterizes the time to failure in constant strain conditions and would correspond to the total time at constant strain over the cycles during our experiments. This interpretation is supported by some tests (not shown), where the material was stretched in the rubbery state and then kept at constant strain at high temperature $\left(65^{\circ} \mathrm{C}\right)$ : the material showed consistent failure after few minutes.

The experimental data plotted in this section showed that the measured constrained or free recoveries at the first cycle are representative of the recoveries of the subsequent cycles. This result was shown to apply whether the material had been deformed at low or high temperatures. Therefore, chemically crosslinked polymers can be good candidates for multicycle applications and a single cycle is needed to characterize their thermomechanical recovery properties. 


\section{Favorable experimental conditions for a high stress peak during constrained recovery}

In the previous section, it was shown that after submitting the material to a pre-strain at a moderately low temperature, a stress peak was recorded at the glass transition temperature during constrained recovery conditions. This section aims at determining the favorable conditions for enhancing this stress peak, which may be an asset in the case of free recovery under external constraint.

\section{Temporary shape fixation temperature}

The effect of the pre-strain temperature on the constrained recovery has been investigated previously. ${ }^{23}$ In order to confirm these results, the acrylate network was submitted to thermomechanical tests with step 1 characterized by $20 \%$ strain applied at various temperatures from the glassy state $\left(35^{\circ} \mathrm{C}\right)$ to the rubbery state $\left(65^{\circ} \mathrm{C}\right)$. Samples were all submitted to a $5{ }^{\circ} \mathrm{C} / \mathrm{min}$ heating ramp while maintaining the sample length constant during step 4. The stress values recorded during step 4 are plotted in Figure 8. A stress peak is observed for samples strained at $50^{\circ} \mathrm{C}$ and below, which increases as the pre-strain temperature decreases. Moreover, it does not appear necessarily at the glass transition temperature, and it is shifted toward lower temperatures as the temperature of strain application decreases. All these results are in good agreement with the experimental data obtained on a thermoset polyurethane, ${ }^{23}$ and similar results were also obtained on a Poly(methyl methacrylate) (PMMA). ${ }^{27}$ Nevertheless, Sun et al. ${ }^{27}$ did not find the overshoot evolution shown in Figure 8.

At $35{ }^{\circ} \mathrm{C}$, which stands below the onset of the glass transition, an interestingly large stress peak is noted but when pre-strained at such a temperature, the material presents a strain fixity of $90 \%$, while it increases to $93 \%$ at $40{ }^{\circ} \mathrm{C}$ and to $97 \%$ at $45{ }^{\circ} \mathrm{C}$. Therefore, a trade off exists 
between good shape fixity and high resulting stress when looking for the optimal pre-strain temperature.

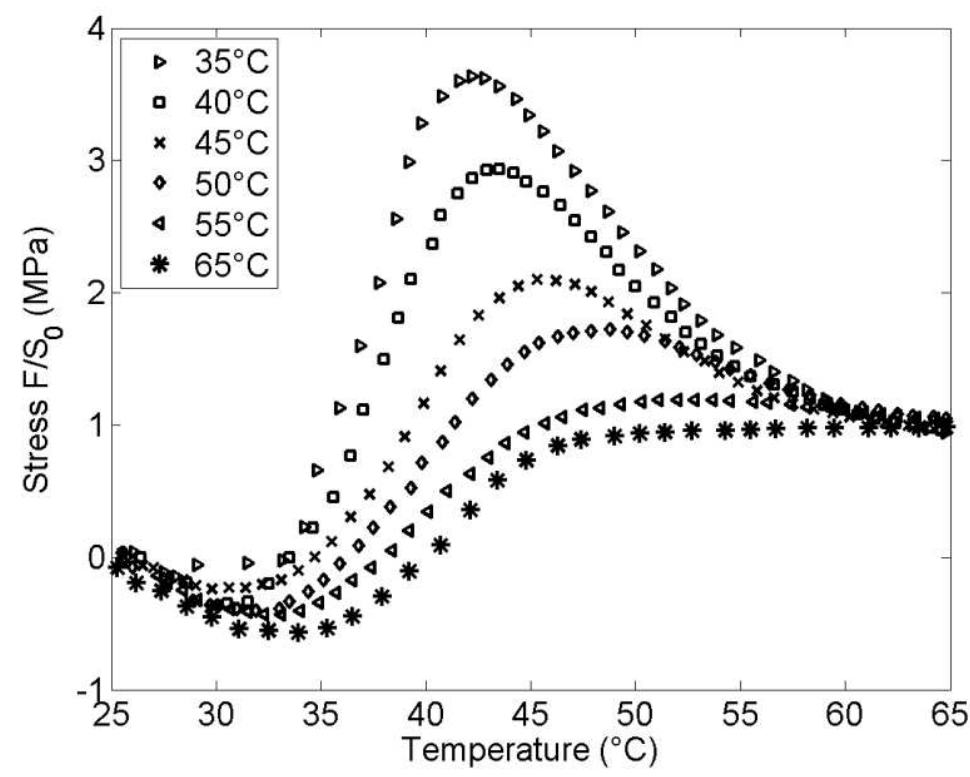

Figure 8: Stress vs. temperature during constrained recovery for samples submitted to a $5{ }^{\circ} \mathrm{C} / \mathrm{min}$ heating recovery after being stretched $20 \%$ at various temperatures during step 1.

\section{Temporary applied strain}

Another way to increase the resulting stress peak during constrained recovery, that has not been studied previously, is to increase the applied pre-strain. In this section, the specimen is submitted to different strains at $40{ }^{\circ} \mathrm{C}$ (within the glass transition) during step 1. After releasing the stress, similar strain fixities of $93 \%$ were recorded for samples strained 20,40 and 55\%. Figure 9 presents the stress evolution when heating the sample at $5{ }^{\circ} \mathrm{C} / \mathrm{min}$ and maintaining its length constant. The stress peak increases significantly with the applied strain. The compression state observed at the beginning of the heating ramp disappears, as the applied strain increases. This explains why Azra et al. ${ }^{23}$ who had submitted their materials to a large strain $(100 \%)$, did not measure any compression during their experiments. Increasing the applied strain appears to have a favorable impact on the amount of resulting stress when heating the material, but it may end with sample break at high temperatures. Actually, each 
sample submitted to $55 \%$ strain broke before reaching $60{ }^{\circ} \mathrm{C}$. These sample failures are consistent with the maximum strains at break recorded during uniaxial tension tests at constant temperatures. The material is expected to break around $55 \%$ strain at $60{ }^{\circ} \mathrm{C}$ from Figure 10, where the material uniaxial strain at break with respect to temperature is shown. Note that Figure 10 is consistent with the strain at break with respect to temperature obtained for acrylate networks submitted to uniaxial tension and also displayed by Safransky and Gall ${ }^{25}$ and by Yackaki et al. ${ }^{28}$

Therefore, applying a large strain increases the stress generated during constrained recovery, but the maximum strain that is sustainable by the material at higher temperatures has to be taken into account in order to avoid undesired material breaks.

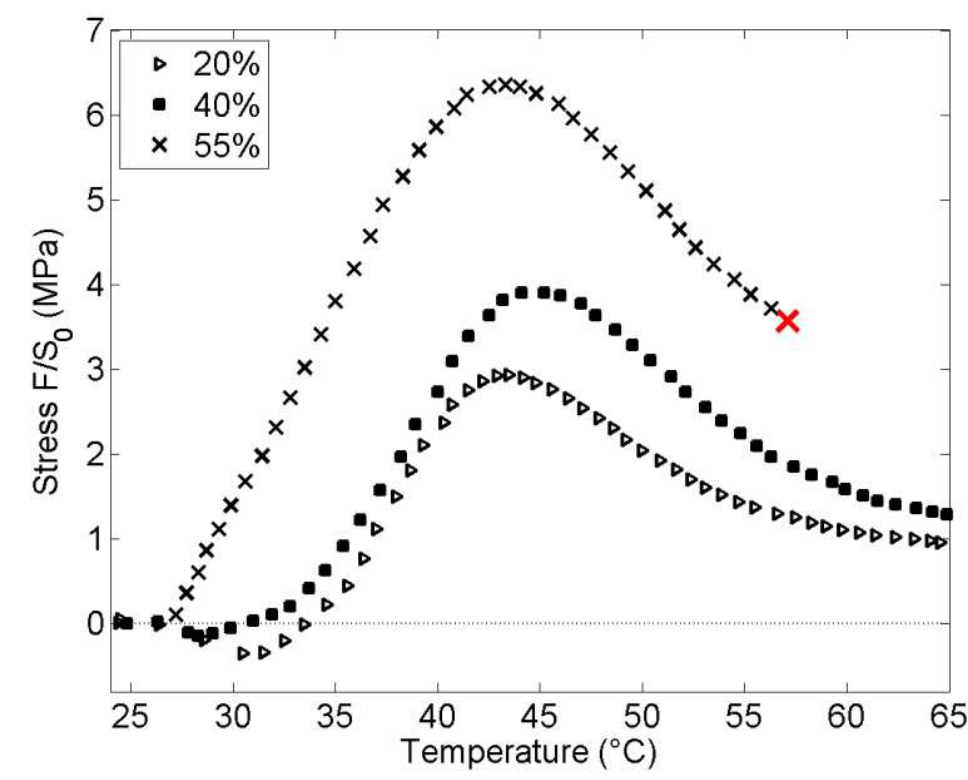

Figure 9: Stress vs. temperature during constrained recovery at $5^{\circ} \mathrm{C} / \mathrm{min}$ heating rate for samples pre-strained $20 \%, 40 \%$ and $55 \%$ at $40^{\circ} \mathrm{C}$ during step 1. 


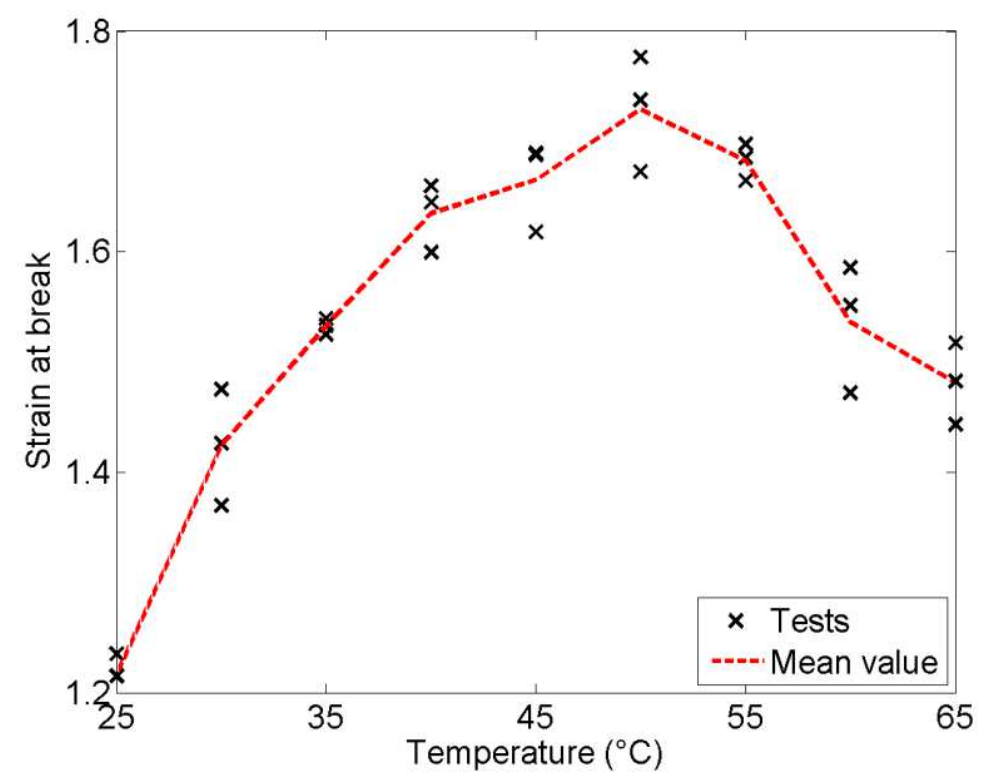

Figure 10: Strain at break with respect to temperature resulting from uniaxial tension tests run at a constant crosshead speed of $10 \mathrm{~mm} / \mathrm{min}$. 3-test mean values shown by the broken line.

\section{Heating rate during constrained recovery}

A steeper heating ramp during constrained recovery tests tends to increase the stress overshoot. ${ }^{11}$ Therefore, acrylate samples were submitted to $20 \%$ strain at $45{ }^{\circ} \mathrm{C}$ during step 1 and, after shape fixation and stress release, the samples were heated at $1{ }^{\circ} \mathrm{C} / \mathrm{min}, 5{ }^{\circ} \mathrm{C} / \mathrm{min}$ and $10{ }^{\circ} \mathrm{C} / \mathrm{min}$ while maintaining their lengths constant. The uniaxial stresses recorded while heating the samples are shown in Figure 11. An increase of the stress overshoot and its shift toward higher temperatures when the temperature heating rate is increased has been observed which is consistent with Castro el al. ${ }^{11}$ and Qi et al. ${ }^{29}$ These results could not be explained by the material thermo-viscoelasticity only, and the coefficient of thermal expansion has been shown in the simulations of Chen and Nguyen ${ }^{30}$ to affect the stress overshoot. Since the coefficient of thermal expansion of our material depends strongly on the heating rate, this may explain the observed effect on the overshoot shown in Figure 11. It may also be noted that the 
heating rate seems to have little effect on the compression exhibited at moderately low temperature.

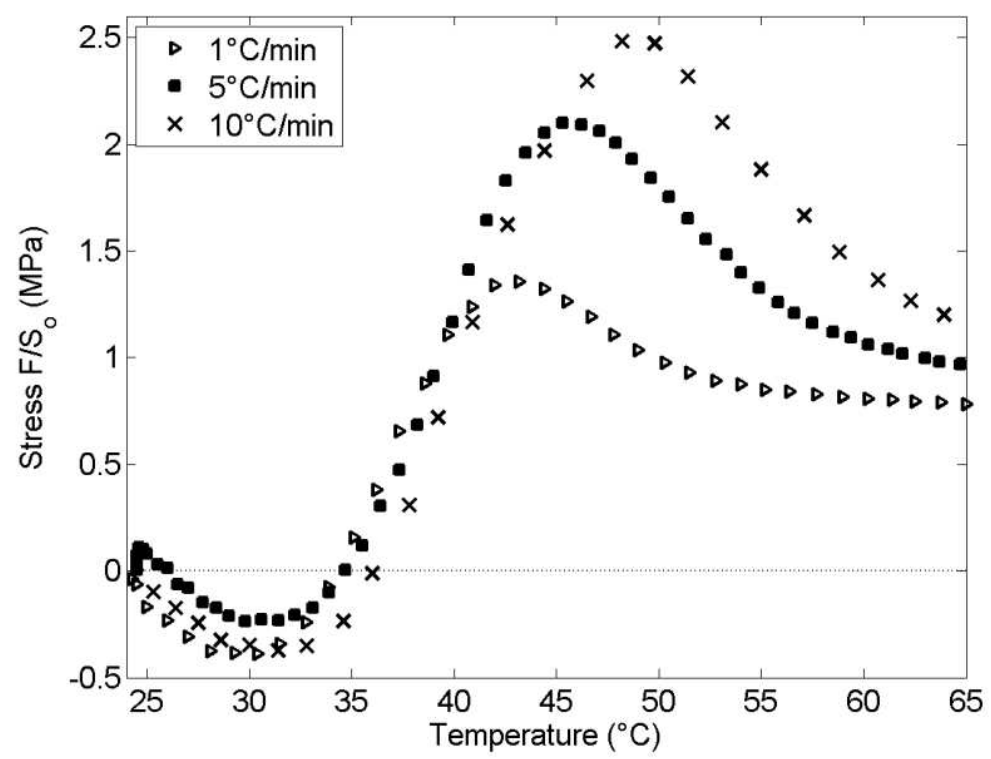

Figure 11: Stress vs. temperature during constrained recovery with various heating rates for samples pre-strained $20 \%$ at $45^{\circ} \mathrm{C}$.

\section{Molecular relaxation during deformation}

The stress peak observed on samples strained at moderately low temperatures can be interpreted by the limited structural relaxation in the glassy state. ${ }^{31}$ In order to validate this interpretation, four samples were submitted to $20 \%$ strain at $40{ }^{\circ} \mathrm{C}$ while allowing more or less molecular relaxation before cooling at constant strain. The first sample was strained at 10 $\mathrm{mm} / \mathrm{min}$ and slowly cooled down to room temperature in approximately 30 minutes. The second sample was strained at $0.3 \mathrm{~mm} / \mathrm{min}$, thus allowing more molecular relaxation during the loading step, and then it was cooled down slowly. The third sample was strained at 10 $\mathrm{mm} / \mathrm{min}$ and maintained at $20 \%$ strain during one hour at $40{ }^{\circ} \mathrm{C}$ before cooling down slowly. Finally, the last sample was deformed at a slow crosshead speed of $0.3 \mathrm{~mm} / \mathrm{min}$ and held for one hour at $40^{\circ} \mathrm{C}$ before letting the sample cooling down slowly to room temperature. All 
samples were then submitted to the same heating rate of $5{ }^{\circ} \mathrm{C} / \mathrm{min}$ while maintaining their length constant. The resulting stress with respect to temperature is displayed in Figure 12. Allowing the material to undergo some stress relaxation leads to a significantly lower stress overshoot. It may also be also noted that the temperature of stress inversion toward positive values increases when the stress relaxation increases, which results in more compressive states at the beginning of the heating ramp. These experimental results show that the stress overshoot is significantly dependent of structural relaxation, as asserted by some models of the literature..$^{31,32}$

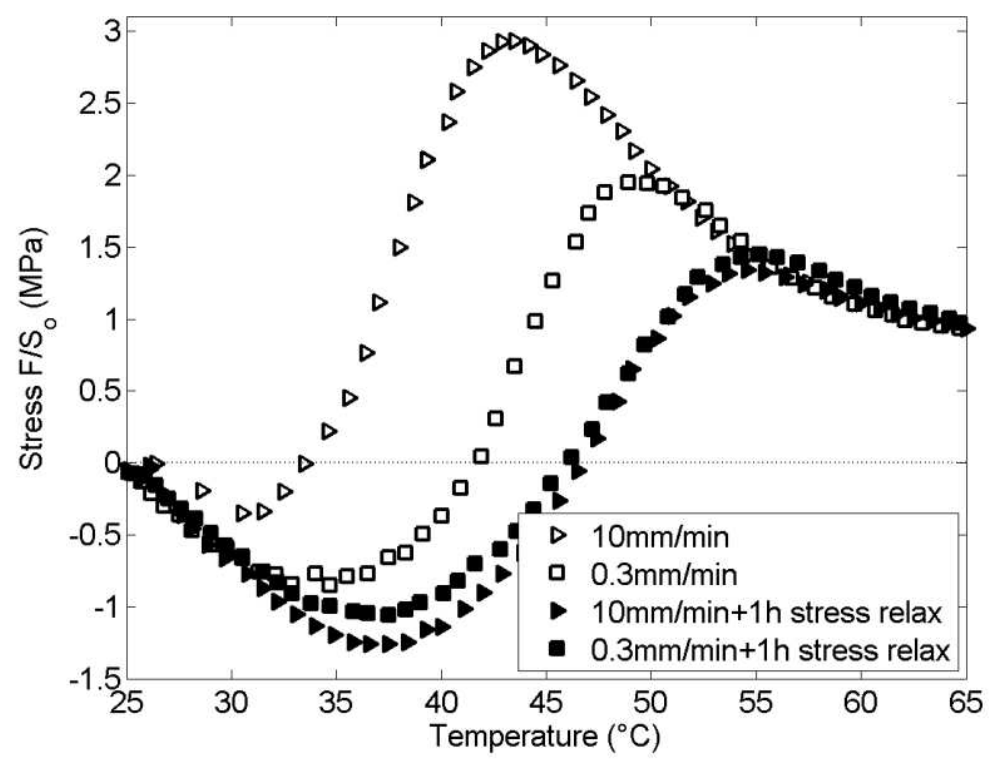

Figure 12: Stress vs. temperature during constrained recovery at $5{ }^{\circ} \mathrm{C} / \mathrm{min}$ following various material stress relaxations during temporary $20 \%$ strain fixation at $40{ }^{\circ} \mathrm{C}$. Relaxation was permitted by slowing the loading strain rate and/or by allowing a stress relaxation of 1 hour at $40{ }^{\circ} \mathrm{C}$ after step 1 .

\section{CONCLUSION}

A rather complete experimental study on the free recovery and constrained recovery of a shape memory crosslinked polymer network has been presented in order to validate and 
supplement the experimental data of the literature. The study aimed at better understanding the potentiality and the limits of chemically crosslinked polymers for future shape memory applications.

On one hand, it was shown that crosslinked networks are good candidates for multicycle shape memory applications since the kinetics of their free or constrained recoveries are the same at the first cycle and at the subsequent cycles. Therefore, a single thermocycle is enough to characterize the shape memory kinetics. On the other hand, for shape memory applications with external constraints, it was shown that it is possible to increase the stress response of the material during constrained recovery. The ideal conditions are summarized as follows: (i) decreasing the temporary shape fixation temperature below the glass transition temperature while keeping a reasonable large shape fixation, (ii) increasing the pre-strain as much as possible without being too close to the strain at break, (iii) limiting the strain relaxation during pre-strain application, fixation and recovery, and finally (iv) increasing the heating rate during shape recovery. Among these parameters, lowering the temperature of pre-strain fixation was noticed to have the strongest effect on the constrained stress recovery. 


\section{ACKNOWLEDGMENT}

This work was supported by the French "Agence Nationale de la Recherche" through project REFORM 10-JCJC-0917.

\section{BIBLIOGRAPHY}

1. Feninat, F.; Laroche, G.; Fiset, M.; Mantovani, D. Adv. Eng. Mater. 2002, 4, 91-104.

2. Gall, K.; Kreiner, P.; Turner, D.; Hulse, M. J. Microelectromec. Syst. 2004, 13, 472483.

3. Lin, J.; Knoll, C.; Willey, C. Shape Memory Rigidizable Inflatable (RI) Structures for Large Space Systems Applications, Structures, Structural Dyn. Mat. Conf, Newport, Rhode Island, USA, 2006.

4. Sokolowski, W.; Tan, S. J. Spacecraft and Rockets, 2007, 44, 750-754.

5. $\mathrm{Hu}$, J. Shape Memory Polymers and Textiles, CRC press Inc., Cambridge, UK, 2007

6. Hu, J.; Zhu, J.; Huahua, H.; Lu, J. Prog. Pol. Sci. 2012, 37, 1720-1763.

7. Serrano, M.; Ameer, G. Macromol. Biosc, 2012, 12, 1156-1171.

8. Tobushi, H.; Hashimoto, T.; Hcayashi, S.; Yamada, E. J. Intel. Mater. Syst. Struc. 1997, $8,711-718$.

9. Liu, Y.; Gall, K.; Dunn, M.; Greenberg, A.; Diani, J. Inter. J. Plast. 2006, 22, 279313.

10. Feldkamp, D.; Rousseau, I. Macromol. Mater. Eng. 2010, 295, 726-734.

11. Castro, F.; Westbrook, K.; Long, K.; Shandas, R. Mec. Time-Depend. Mater. 2010, $14,219-241$.

12. Diani, J.; Gilormini, P.; Fredy, C.; Rousseau, I. Inter. J. Sol. Struc. 2012, 49, 793.

13. Nguyen, T. Pol. Rev. 2013, 53, 130-170.

14. Heuchel, M.; Sauter, T.; Kratz, K.; Leindlein, A. Journal Pol. Sci., Part B: Pol. Phys. 2013, 51, 621-637. 
15. Barikani, M.; Zia, K.; Bhatti, I.; Zuber, M.; Bhatti, H. Carbo. Pol. 2008, 74, 621-626.

16. Luo, X.; Mather, P. Macromol. 2009, 45, 7251-7253.

17. Leonardi, A.; Fasce, L.; Zucci, I.; Hoppe, C.; Soul, E.; Prez, C.; Williams, R. Europ. Pol. Journal, 2011, 47, 362-369.

18. Rousseau, I.; Xie, T. Journal Mater. Chem. 2010, 20, 3431-3441.

19. Feldkamp, D.; Rousseau, I. Macromol. Mater. Eng., 2011, 296, 1128-1141.

20. Volk, B.; Lagoudas, D.; Maitland, D. Smart Mater. Eng. 2011, 20, 094004-094019.

21. Gall, K.; Yakacki, C.; Liu, Y.; Shandas, R.; Willett, N.; Anseth, K. Journal of Biomed. Mater. Res. 2005, 73A, 339-348.

22. Wong, Y.; Venkatraman, S. Acta Materialia, 2010, 58, 49-58.

23. Azra, C.; Plummer, C.; Manson, J. Smart Mater. Struc. 2011, 20, 082002-082012.

24. Choi, J.; Ortega, A.; Xiao, R.; Yackaki, C.; Nguyen, T. Polymer, 2012, 53, 2453-2464.

25. Safransky, D.; Gall, K. Polymer, 2008, 49, 4446-4455.

26. Smith, T. Journal Pol. Sci., PartA: Pol. Chem. 1963, 1, 3597-3615.

27. Sun, L.; Huang, W.; Wang, C.; Zhao, Y.; Ding,Z.; Purnawali, H. Journal Pol. Sci., PartA: Pol. Chem. 2011, 49, 3574-3581.

28. Yackaki, C.; Willis, S.; Luders, C.; Gall, K. Adv. Eng. Mater. 2008, 10,112-119.

29. Qi, H.; Nguyen, T.; Castro, F.; Yackaki, C.; Shandas, R. J. Mech. Phys. Solids, 2008, $56,1730-1751$.

30. Chen, X.; Nguyen, T. Mech. Mater. 2011, 43, 127-138.

31. Nguyen, T.; Qi, H.; Castro, F.; Long, K. J. Mech. Phys. Solids, 2008, 56, 2792-2814.

32. Xiao, R.; Choi, J.; Lakhera, N.; Yackaki, C.; Frick, C.; Nguyen, T. J. Mech. Phys. Solids, 2013, 61, 1612-1635. 